\title{
Motivation and Interlanguage Pragmatics in Iranian English Language Learners
}

\author{
Hassan Rasouli Khorshidi ${ }^{1}$ \& Abdolreza Bagherzadeh Nimchahi ${ }^{1}$ \\ ${ }^{1}$ Department of English, Neka Branch, Islamic Azad University, Neka, Iran \\ Correspondence: Hassan Rasouli Khorshidi, Department of English, Neka Branch, Islamic Azad University, \\ Neka, Iran. Tel: 919-739-766-137. E-mail: Rasouli222@gmail.com
}

Received: March 3, 2013 Accepted: April 17, 2013 Online Published: May 8, 2013

doi:10.5539/elt.v6n6p86 URL: http://dx.doi.org/10.5539/elt.v6n6p86

\begin{abstract}
It is generally believed that interlanguage pragmatics and motivation play important roles in learning. Motivation is important because it determines the extent of the learner's active involvement and attitude toward learning. The major purpose of this study was to investigate the impact of integrative and instrumental motivation on the development of interlanguage pragmatics (ILP) in Iranian English language learners. A secondary goal of this study was to assess the effect of the type of motivation on pragmatic transfer. To this end, the Attitude/Motivation Test Battery (AMTB) developed by Gardner (1985) was given to the students to distinguish learners with integrative and instrumental motivation. Finally, 40 integratively and 40 instrumentally motivated learners were selected as participants. Then, a Discourse Completion Task (DCT) regarding pragmatic transfer developed by the researchers was administered to the two groups. Two weeks later another interlanguage pragmatics Discourse Completion Task (DCT) was administered in order to elicit the required data from both groups. The findings demonstrate that there is a significant relationship between type of motivation and interlanguage pragmatic development and the amount of negative pragmatic transfer as well. More precisely, this study revealed that integratively motivated learners performed significantly better than instrumentally motivated learners in both ILP development and pragmatic transfer.
\end{abstract}

Keywords: integrative and instrumental motivation, interlanguage pragmatics, negative pragmatic transfer

\section{Introduction}

One distinguishing feature between native and non-native speakers is their proficiency in interlanguage pragmatics. It is often the case that even advanced language learners who have learned a great deal of words, idioms, and grammar, fail to communicate meaning appropriately in certain contexts. A number of individual factors such as motivation can be crucial to language learning. Motivation, highlighted by Ames and Ames (1989) is important because it determines the extent of the learner's active involvement and attitude toward learning. According to Gardner (1985) motivation is "the extent to which an individual works or strives to learn the language because of a desire to do so and the satisfaction experienced in this activity" (p. 10).

Motivation can be regarded as the most important determiner in learning a second or foreign language successfully $(\mathrm{Xu}, 2010)$. Motivation as a desire to achieve a certain goal is regarded as the force that pushes a learner forward to accomplish a task. Motivation is often seen as a key learner variable because without it the outcome of an activity may not be desirable enough. Indeed, most other learner variables presuppose the existence of at least some degree of motivation. Motivation can be promoted consciously, which is good news for L2 teachers and learners. It means that by employing certain methods, it is possible to enhance learners' motivation. Therefore, skills in motivating learners are an important aspect of any teacher's methodological repertoire (Schmitt, 2002).

\section{Conceptual Framework of Motivation}

Motivation is usually categorized based on two different perspectives: the purpose of doing an activity and the source of the desire to succeed in accomplishing a task. Regarding purpose, motivation can be integrative or instrumental. Gardner and Lambert (1972) defined integrative motivation as positive attitudes and feelings toward the target language group and instrumental motivation as the potential utilitarian gains of L2 proficiency, such as getting a better job or higher salary). Regarding source, there are two kinds of motivation: intrinsic and 
extrinsic. Pintrich and Schunk (2002) stated that intrinsic motivation refers to "motivation to engage in an activity for its own sake" (p. 245) while extrinsic motivation indicates "motivation to engage in an activity as a means to an end" (p. 245).

Redfield and Levin (2009) held that the terms "instrumental" and "integrative" motivation were developed by Gardner and Lambert in 1959 in order to explain different motivational orientations. Idawati (2010) notes that while an integratively motivated person is learning English through a desire to learn about the culture and its people and also likes to integrate within the target language community, an instrumentally motivated language learner aims to achieve some other goals, for example, learning to speak English for better job opportunities.

Regarding the impact of these two types of motivation on language learning, a number of studies have been conducted till now. While some scholars believe that instrumental motivation facilitates language learning (e.g., see Idawati, 2010; Lukmani, 1972; Warden \& Lin, 2000), others believe that integrative motivation is an asset in language learning (Gardner, Day \& Maclntyre, 1992; Sadighi \& Maghsudi; Strong, 1984). Moreover, some research studies have also revealed that both integrative and instrumental motivation facilitate learning (e.g., see Dörnyei, 1990; Gardner \& MacIntyre, 1991)

Schmidt (1995) postulated that motivation and some other affective factors play key roles in learners' pragmatic development. He also emphasizes that learners with higher motivation like to establish relationship with the speakers of the target language and are willing to focus more on pragmatic norms.

\section{Interlanguage Pragmatics (ILP)}

As a part of linguistics, syntax studies sentences, semantics studies propositions, while pragmatics is the study of linguistic acts and the contexts in which they are performed (Stalnaker, 1998). Carnap (1942, as cited in Huang, 2007 , p. 2) states that "syntax is the most and pragmatics is the least abstract, with semantics lying somewhere in between". Consequently, syntax provides input to semantics and semantics provides input to pragmatics (Recanati, 2004). In contemporary linguistics, pragmatics is a quickly growing field and new discipline compared to other linguistic topics. Huang (2007) states that pragmatics deals with the systematic study of meaning regarding the use of language.

When pragmatics is studied within two languages the term interlanguage pragmatics (ILP) seems more appropriate i.e. as a domain within L2 studies, pragmatics is usually referred to as interlanguage pragmatics. Interlanguage pragmatics studies the interlanguage, which is related to the second language acquisition and pragmatics which is the study of language in context. Therefore, ILP studies the second language acquisition in its context. The definition presented by Kasper and Rose (2002) shows the interdisciplinarity or hybrid nature of interlanguage pragmatics as belonging both to pragmatics and SLA as well:

As the study of second language use, interlanguage pragmatics examines how nonnative speakers comprehend and produce actions in a target language. As the study of second language learning, interlanguage pragmatics investigates how L2 learners develop the ability to understand and perform actions in a target language (p. 5).

The definition above by Kasper and Rose highlights that there are two important aspects in ILP research which focuses on both production and comprehension aspects of language as part of learners' pragmatic competence in the L2. The second part of this definition shows that ILP is also concerned with the development of pragmatic competence. On the other hand, as a subject of pragmatics, ILP is a sociolinguistic, psycholinguistic or simply linguistic issue that mostly depends on how one defines the scope of pragmatics (Kasper \& Blum-Kulka, 1993).

\subsection{Transfer and Motivation}

Research suggests that transfer and motivation seem to be mutually supportive in creating an optimal learning environment. If learners perceive what they are learning to be relevant and transferable to other situations, they will find learning meaningful, and their motivation to acquire the skill or knowledge will increase. Similarly, for transfer to take place, the learners must be motivated to do two things. First, they must be able to recognize opportunities for transfer (Prawat, 1989); second, they need to possess the motivation to take advantage of these opportunities (Pea, 1988). The challenge of teaching is thus to simultaneously enhance transfer and motivation so that they both support learning. To do this, teachers need to first understand the nature of transfer and the nature of motivation.

\subsection{Historical View of Language Transfer}

The emergence of transfer dates back to the Contrastive Analysis (CA) period, which was linked to behaviorist views of language learning and to structural linguistics. The effect of L1 on L2, mainly at the level of pronunciation, led researchers in the 1960s toward the Contrastive Analysis Hypothesis (CAH). In those days 
there were two widely held beliefs. Firstly, that the mother tongue strongly influenced the L2. Secondly, that this influence was negative. Accordingly, contrastive analysts believed that the L1 interfered with L2 learning. The $\mathrm{CAH}$ suggested that where two languages were different, there would be negative transfer or interference since learners would experience difficulty that would result in the production of errors; and that where two languages were similar, there would be positive transfer since learning would be facilitated and no errors would result (Franch, 1998). Franch continued that this led to different ways of accounting for the role of the first language in target language. In one, researchers treated transfer as one of several processes involved in SLA, moving from a product-oriented to a process-oriented approach to account for L1 influence.

\subsection{Pragmatic Transfer}

When learners are learning a new language, they already know at least one language with a repertoire of information and experience that will certainly affect the learning and using the new language. The interaction between the old information - the first language - and the new information - any subsequent language one may learn - is at the heart of the phenomenon of transfer (Bou-Franch, 2012, p. 4622).

Trying to define pragmatic transfer comprehensively is problematic since both parts of the phrase are in themselves problematic. They have been used with different meanings and/or with similar meanings but under different labels. As to the notion of transfer, its evolution, and the alternative labels that have been suggested by different researchers, finally commented on how this notion is understood nowadays. As to the notion of pragmatics, there is disagreement about how to define the scope of interest in pragmatic transfer. Wolfson (1989) referred to pragmatic transfer as sociolinguistic transfer but Beebe, Takahashi and Uliss-Weltz (1990) called it sociocultural or cross-cultural influence. Odlin (1989) described it as transfer in conversational features or as discourse transfer, while Kasper (1992) considers it as the influence that previous knowledge has on the use and acquisition of L2 pragmatic knowledge. Kasper (1992) argued that "pragmatic transfer in interlanguage pragmatics shall refer to the influence exerted by learners' pragmatic knowledge of languages and cultures other than L2 on their comprehension, production and learning of L2 pragmatic information" (p. 207).

\section{Statement of the Problem}

In this research the researchers studied interlanguage pragmatics, "which is both a sub-discipline of second language acquisition research and pragmatics" (Moreno, 2001, p. 129). As a sub-discipline of L2 acquisition research, ILP is different from other interlanguage studies such as syntax and semantics. Moreno adds that ILP as a subset of pragmatics, covers "an area of sociolinguistics, psycholinguistics or simply linguistics depending on how one describes the scope of pragmatics" (p. 129). Kasper (1996) stated that ILP deals with nonnative speakers' understanding and production of linguistic acts in the target language and the way they acquire the L1 pragmatic knowledge. Although there was a plethora of studies on the role of transfer in syntax, morphology, and semantics, there has been little theoretical consideration of transfer in ILP (Kasper, 1992).

Due to the social nature of L2 motivation, motivation to learn a second language is very different from the motivation to learn any other school subjects. This is because an L2 is not only a communication code, but also a representative of the L2 culture where it is spoken. Therefore, learning a second language always to some extent entails learning a second culture (Schmitt, 2002). Williams (1994) argues that the learning of a foreign language is not just learning skills, or a system of rules, or a grammar; it also includes a change in self-image, an adoption of new social and cultural behaviors. Therefore, it has a significant effect on the social nature of the learner.

It seems notable to mention that learners may well be reluctant to start learning the language of a cultural group towards which they have truly negative feelings, and similarly, having favorable attitudes towards a language community may well increase learners' motivation. The social psychological approach they adopted is still one of the most influential directions in the study of L2 motivation (Schmitt, 2002). As a result, more research studies are required to investigate the relationship between motivation and interlanguage pragmatics to see which type of motivation is more effective in training more pragmatically proficient L2 learners.

\section{Research questions}

$\mathrm{RQ}_{1}$ : Does the type of motivation affect the development of language learners' interlanguage pragmatic competence?

$\mathrm{RQ}_{2}$ : Does the type of motivation affect negative pragmatic transfer?

\section{Methodology}

\subsection{Participants}

A total number of 80 Iranian learners of the English language were selected to participate in the present study. 
One group included 40 learners with integrative motivation and the other group of 40 was selected with instrumental motivation. The participants in this study were selected from the intermediate level at the Iran Language Institute in Sari, a city in the north of Iran. The participants of this study were chosen among those with no residency in any foreign English speaking countries to make sure that their possible interlanguage development was not related to residing abroad.

\subsection{Materials and Procedures}

In order to choose a homogenous group of learners at intermediate level, first and foremost, a proficiency test was conducted to a group of 254 students at the Iran Language Institute. From among the students who had taken the proficiency test, 115 students were selected as homogenous students to take the Attitude/Motivation Test Battery (AMTB) designed by Gardner (1985) to distinguish integratively and instrumentally motivated learners. From the 115 students, 40 integratively and 40 instrumentally motivated learners with highest scores in each group were selected as the participants. A week later, a Discourse Completion Task (DCT) on pragmatic transfer (cf. Appendix A) was administered to the students. This test was prepared by the researchers specifically for this study and included 20 situations with transfer possibility from Iranian English language learners. More than thirty colleagues helped the researchers to develop this pragmatic transfer test. The reliability and validity of the test was testified by the researchers at the language institutes in Iran. Two weeks later another Discourse Completion Task (DCT), developed by Jianda (2006) on interlanguage pragmatics was given to both groups of participants in order to measure their progress in interlanguage pragmatics. The papers were scored by two native speakers and an experienced EFL teacher from Iran. Moreover, the answers provided by the native speakers helped to judge on the acceptable answers provided by the participants for each item.

\section{Results}

The elicited data was submitted to the SPSS software for statistical analysis. Using the independent sample t-test, the output consisted of the following results pertaining to each research question.

$R_{Q_{1}}$ : Does the type of motivation affect the development of language learners' interlanguage pragmatic competence?

Table 1. Group Statistics

\begin{tabular}{|c|c|c|c|c|}
\hline $\begin{array}{l}\text { Type of } \\
\text { Motivation }\end{array}$ & $\mathbf{N}$ & Mean & $\begin{array}{l}\text { Std. } \\
\text { Deviation }\end{array}$ & Std. Error Mean \\
\hline Integrative & 40 & 16.6 & 1.33 & .211 \\
\hline Instrumental & 40 & 15.1 & 1.56 & .247 \\
\hline
\end{tabular}

Table 2. Independent Samples Test (t-test for Equality of Means)

\begin{tabular}{|c|c|c|c|c|c|}
\hline & \multirow[t]{2}{*}{$\mathrm{t}$} & \multirow[t]{2}{*}{ df } & \multirow[t]{2}{*}{$\begin{array}{l}\text { Sig. } \\
\text { (2-tailed) }\end{array}$} & \multicolumn{2}{|c|}{$\begin{array}{l}95 \% \text { Confidence } \\
\text { Interval of the } \\
\text { Difference }\end{array}$} \\
\hline & & & & Lower & Upper \\
\hline $\begin{array}{l}\text { Equal } \\
\text { variances } \\
\text { assumed }\end{array}$ & 4.609 & 78 & .000 & .32542 & .85214 \\
\hline $\begin{array}{l}\text { Equal } \\
\text { variances } \\
\text { not } \\
\text { assumed }\end{array}$ & 4.609 & 76.115 & .000 & .32542 & .85189 \\
\hline
\end{tabular}

Tables 1 and 2 show the statistical results obtained pertaining to the overall success of the two groups in pragmatic competence test. As table 1 illustrates, the mean for the integrative group was 16.6, while the mean for the instrumental group was 15.1. This indicates that the integrative learners' overall gain was higher than their counterparts concerning pragmatic competence. Moreover, as it can be seen, the Sig was less than .05. Therefore, 
on the whole, it can be concluded that the difference between the two means was statistically significant. Consequently, the obtained results indicate that learners with integrative motivation performed better on the test of pragmatics than instrumentally motivated ones. This may be due to the profound effects of their intention to integrate in learning a language. Since integratively motivated learners are more willing to integrate with the target culture and community, this may help them make more progress in pragmatic competence.

$\mathrm{RQ}_{2}$ : Does the type of motivation affect negative pragmatic transfer?

Table 3. Group Statistics

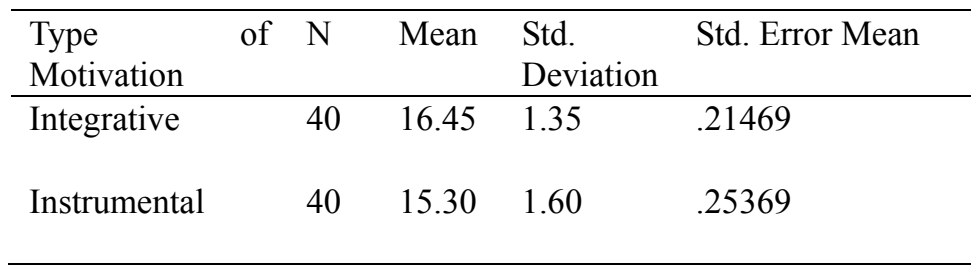

Table 4. Independent Samples Test (t-test for Equality of Mean)

\begin{tabular}{lccclc} 
& $\mathrm{t}$ & $\mathrm{df}$ & $\begin{array}{l}\text { Sig. } \\
\text { (2-tailed) }\end{array}$ & $\begin{array}{l}\text { 95\% } \\
\text { Interval } \\
\text { Difference }\end{array}$ & $\begin{array}{c}\text { Confidence } \\
\text { of the }\end{array}$ \\
\cline { 5 - 6 } & & & & Lower & Upper \\
\hline $\begin{array}{l}\text { Equal } \\
\begin{array}{l}\text { variances } \\
\text { assumed }\end{array}\end{array}$ & 3.460 & 78 & .001 & .48837 & 1.81163 \\
\hline $\begin{array}{l}\text { Equal } \\
\text { variances } \\
\text { not } \\
\text { assumed }\end{array}$ & 3.460 & 75.923 & .001 & .48808 & 1.81192 \\
\hline
\end{tabular}

Table 3 depicts the results regarding the participants' pragmatic transfer. The difference between the two means supports that the integrative groups got better marks in the test with the mean of 16.45 which indicates that they made less negative transfer than instrumentally motivated learners. Moreover, table 4 illustrates that the Sig was .001 which was less than .05 . It means that the difference between the two means is statistically significant. As a result, it can be concluded that, the learners with integrative motivation performed better than the learners with instrumental motivation. In other words, the learners with integrative motivation showed less negative transfer. Again, the fact behind this can be because of the nature of integration in the target culture and community. Based on the findings, this research study supports the belief that integrative motivation is an asset to learners for successful language learning.

\section{Discussion}

This study was designed to address the important issue of pragmatic development with regard to the type of motivation of Iranian EFL learners. It aimed to determine whether interlanguage development is affected by the type of motivation. Research has shown that learners' L1 pragmatic knowledge significantly influences their pragmatic performance in the target language (Kasper, 1992; Wannaruk, 2008). Negative pragmatic transfer involves utilizing the sociolinguistic rules of speaking in one's native speech community when interacting within the host speech community (Wolfson, 1989). Literature strongly supports that nonnative speakers' comprehension and production of linguistic action is considerably influenced by their L1 pragmatic knowledge (Kasper, 1992; Wannaruk, 2008).

Most of the problems that foreign language learners encounter in communication are mainly pragmatic since exposure to authentic language use is very scarce and language teachers and textbook writers often neglect developing pragmatic knowledge in instructional setting, focusing on merely linguistic knowledge (Usó-Juan \& Martínez-Flor, 2006). In contrast to a second language (SL) context in which learners have more exposure to the target language and more opportunities to use it in real-life exchanges, a foreign language (FL) environment fails to provide learners with opportunities for genuine communication in the target language. Actually, the classroom 
setting is the only source of input and instances of target pragmatic behaviour. This situation inevitably prepares the ground for pragmatic violations when functioning in the target language. One of the effective ways to minimize pragmatic failure is to arrange learning opportunities which are conducive to the development of pragmatic competence which is "the knowledge of the linguistic resources, sequential aspect of speech acts and the appropriate contextual use of linguistic resources" (Barron, 2003, p.10). Therefore, as EFL learners are learning the language out of its real context, some supplementary input of pragmatics seems inevitable.

What can language teachers do to teach pragmatics and to decrease the possibility of negative transfer? Schmidt (1993) points out that the necessary condition for pragmatic learning to take place is conscious attention to the pragmalinguistic and sociopragmatic information to be acquired. Consequently, Schmidt, together with other authors, such as Thomas (1983) or Richards and Sukwiwat (1983) among others claim that a direct approach to the teaching of the pragmatics of the L2 is compulsory. Bou-Franch (1998) believes that "if the nonnative speakers are consciously aware of the pragmalinguistic and sociopragmatic similarities and differences between their native and target languages, then negative outcomes of transfer will most probably be inhibited" (p. 5). Therefore, teachers are responsibility for providing the students with the necessary tools to help them make the appropriate pragmalinguistic and sociopragmatic decisions in the target language. The present researchers would like to suggest that one way in which teachers can help students become pragmatically aware and improve their pragmatic knowledge is by providing them with pragmatic input.

In closing, since the most important aim of the language learning and teaching curriculum is to facilitate language learning, it is hoped that research in second language pragmatics will not only improve the understanding of pragmatic development in speech act realization but will also enable applied linguists, curriculum developers, and teachers to incorporate effective methods of teaching pragmatics in the EFL classroom based on the type of motivation.

\section{Acknowledgements}

The researchers are grateful to the head of the Iran Language Institute permitting them conduct this research there. Our special thanks also are to our colleagues at the Iran Language Institute for both helping us administer the tests and develop the negative pragmatic transfer test. Without their help it would not have been possible to design a test appropriate for this study. And the last but the least, we owe our special thanks to all the respondents for having responded to the questionnaire with an immense level of spirit.

\section{References}

Ames, C., \& Ames, R. (1989). Research in motivation in education. San Diego: Academic Press.

Barron, A. (2003). Acquisition in interlanguage pragmatics. Amsterdam, Netherlands: John Benjamins.

Beebe, L. M., Takahashi, T., \& Uliss-Weltz, J. (1990). Pramagmatic Transfer in ESL Refusals. In R. C. Scarcella, E. S. Anderson, \& S. D. Krashen (Eds), Developing Communicative Competence in a Second Language (pp. 55-73). New York: Newbury House.

Bou-Franch, P. B. (1998). On pragmatic transfer. Studies in English Language and Linguistics, 9, 5-20.

Bou-Franch, P. (2012). Pragmatic transfer. The Encyclopedia of Applied Linguistics. Blackwell Publishing Ltd. http://dx.doi.org/10.1002/9781405198431.wbeal0932

Dörnyei, Z. (1990). Conceptualizing Motivation in Foreign-Language Learning. Language Learning, 40(1), 45-78. http://dx.doi.org/10.1111/j.1467-1770.1990.tb00954.x

Gardner, R. C. (1985). Social psychology and second language learning: The role of attitudes and motivation. London: Edward Arnold.

Gardner, R. C., Day, J. B., \& Maclntyre, P. D. (1992). Integrative Motivation, Induced Anxiety, and Language Learning in a Controlled Environment. Studies in Second Language Acquisition, 14(02), 197-214. http://dx.doi.org/10.1017/S0272263100010822

Gardener, R. C., \& Lambert, W. E. (1972). Attitudes and motivation in second language learning. Rowley, Massachusetts: Newbury House Publishers.

Gardner, R. C., \& MacIntyre, P. D. (1991). An Instrumental Motivation in Language Study. Studies in Second Language Acquisition, 13(01), 57-72. http://dx.doi.org/10.1017/S0272263100009724

Han, Z. (2009). Interlanguage and fossilization: Towards an analytic model. Contemporary Applied Linguistics, $1,137-162$.

Huang, Y. (2007). Pragmatics. London, England: Oxford University Press. 
House, J. (1993). Toward a model for the analysis of inappropriate responses in native/non-native interactions. In G. Kasper, \& S. Blum-Kulka (Eds.), Interlanguage Pragmatics (pp. 161-183). New York: Oxford University Press.

Idawati, K. (2010). The analysis of the students' integrative and instrumental motivatrion in learning English. Retrieved from http://my.opera.com/kurnia1104/blog/show.dml/16716142

Jianda, L. (2006). Assessing EFL learners' interlanguage pragmatic knowledge: Implications for testers and teachers. Reflections on English language teaching, 5(1), 1-22.

Kasper, G. (1992). Pragmatic transfer. Second language research, 8(3), 203-231. http://dx.doi.org/10.1177/026765839200800303

Kasper, G. (1996). Introduction: Interlanguage pragmatics in SLA. Studies in Second Language Acquisition, 18(02), 145-148. http://dx.doi.org/10.1017/S0272263100014856

Kasper, G., \& Blum-Kulka, S. (1993). Interlanguage pragmatics: An introduction. In Kasper, G., \& S. Blum-Kulka (Eds.), Interlanguage pragmatics. New York, NY: Oxford University Press.

Kasper, G., \& Rose, K. R. (2002). Pragmatic Development in a Second Language. Malden, MA: Blackwell.

Kasper, G., \& Schmidt, R. (1996). Developmental issues in interlanguage pragmatics. Studies in Second Language Acquisition, 18(2), 149-169. http://dx.doi.org/10.1017/S0272263100014868

Lukmani, Y. M. (1972). Motivation to learn and language proficiency. Language Learning, 22(2), 261-273. http://dx.doi.org/10.1111/j.1467-1770.1972.tb00087.x

Martínez-Flor, A., \& Usó-Juan, E. (2006). A comprehensive pedagogical framework to develop pragmatics in the foreign language classroom: The 6R Approach. Applied Language Learning, 16(2), 39.

Moreno, Á. E. I. (2001). Native speaker-non-native speaker interaction: The use of discourse markers. ELIA, 2 , 129-142.

Odlin, T. (1989). Language Transfer. Cambridge: Cambridge University Press.

Pea, R. D. (1988). Putting knowledge to use. In Raymond S. Nickerson, \& Philip R. Zodhiates (Eds.), Technology in education: Looking toward 2020. Hillsdale, N.J.: Lawrence Erlbaum Associates.

Pintrich, R. M., \& Schunk, D. H. (2002). Motivation in education: Theory, research, and application (2nd ed.). New Jersey: Merrill Prentice Hall.

Prawat, R. S. (1989). Promoting access to knowledge, strategy, and disposition in students: A research synthesis. Review of Educational Research, 59, 1-41. [EJ 399 812]

Recanati, F. (2004). Literal meaning. Cambridge: Cambridge University Press.

Richards, J. C., \& Sukwiwat, M. (1983). Language Transfer and Conversational Competence, Applied Linguistics, 4(2), 113-125. http://dx.doi.org/10.1093/applin/4.2.113

Sadighi, F., \& Maghsudi, N. (2000). The relationship between motivation and English proficiency among Iranian EFL learners. Indian journal of applied linguistics, 26(1), 39-52.

Schmidt, R. (1993). Consciousness, learning and interlanguage pragmatics. In G. Kasper, \& S. Blum-Kulka (Eds.), Interlanguage pragmatics (pp. 21-42). Oxford: Oxford University Press.

Schmidt, R. (1995). Consciousness and foreign language learning: A tutorial on the role of attention and awareness in learning. Honolulu, Hawai'i: University of Hawai'i, Second Language Teaching \& Curriculum Center.

Schmitt. N. (2002). An Introduction to Applied Linguistics. Oxford University Press Inc., New York.

Stalnaker, R. C. (1998). Pragmatics. In A. Kasher (Ed.), Pragmatics. Critical Concepts (Vol. 11) (pp. 55-69). London Routledge.

Strong, M. (1984). Integrative motivation: Cause or result of successful second language acquisition? Language Learning, 34(3), 1-13. http://dx.doi.org/10.1111/j.1467-1770.1984.tb00339.x

Thomas, J. (1983). Cross-Cultural Pragmatic Failure. Applied Linguistics, 4(2), 91-112.

Usó-Juan, E., \& Martínez-Flor, A. (Eds.). (2006). Current trends in the development and teaching of the four language skills (Vol. 29). De Gruyter Mouton.

Wannaruk, A. (2008). Pragmatic transfer in Thai EFL refusals. RELC journal, 39(3), 318-337. 
http://dx.doi.org/10.1177/0033688208096844

Warden, C. A., \& Lin, H. J. (2000). Existence of Integrative Motivation in an Asian EFL Setting. Foreign Language Annals, 33(5), 535-545. http://dx.doi.org/10.1111/j.1944-9720.2000.tb01997.x

Williams, M. (1994). Motivation in Second and Foreign Language Learning: An interactive perspective. Educational and Child Psychology, 11, 77-84.

Wolfson, N. (1981). Invitations, Compliments and the competence of the Native Speaker. International Journal of Psycholinguistics, 8(4), 7-22.

Wong, Y. M. (2011). A study of instrumental and intergrative motivations as factors influencing UTAR third year Chinese undergraduates in learning ESL (Doctoral dissertation, UTAR).

$\mathrm{Xu}$ H. (2010). From EFL to ESL: The influence of context on learners' motivational profiles. 123 Arizona Working Papers in SLA \& Teaching, 17, 123-142.

\section{Appendix A: Interlanguage Negative Transfer Completion Test for Persian Speakers}

Name:

Age:

Gender: Male

Female

\section{Read the situations below and provide your answer in the "You say" section.}

Situation 1: Your friend borrows your pen and then returns it to you.

- You say:

- Expected English native answer: Thanks.

- Predicted Persian native answer: (Ghabeli nadare) It can be yours.

Situation 2: Your friend bought a new shirt and you want to say that he looks good in that shirt.

- You say:

- $\quad$ Expected English native answer: It goes with you.

- Predicted Persian native answer: (Behet miad) It comes with you.

Situation 3: You and your friends are going to the seaside this afternoon. Invite one of your friends to join you.

- You say:

- $\quad$ Expected English native answer: Would you like to go with us?

- Predicted Persian native answer: (Doost dari bahamoon biyay?) Would you like to come with us?

Situation 4: Your classmate asks you "How are you?"

- You say:

- Expected English native answer: Fine thanks (and you?).

- Predicted Persian native answer: (Motshakkeram) Thanks.

Situation 5: Somebody bumps into you and says "I'm sorry".

- You say: 
- Expected English native answer: That's $O K$.

- Predicted Persian native answer: (Khahesh mikonam) You're welcome.

Situation 6: You ask somebody: "Is there a bank near here?" but he doesn't know if there is one and he says:"sorry I don't know."

You say:

- $\quad$ Expected English native answer: Thanks anyway.

- Predicted Persian native answer: (Khahesh mikonam) You're welcome.

Situation 7: At the end of the class you would like to tell your teacher that he have done well.

- You say:

- $\quad$ Expected English native answer: Good job.

- Predicted Persian native answer: (Khaste nabashid) Don't be tired.

Situation 8: On a telephone call you want to make sure that the person whom you are talking to is Tina.

- You say:

- Expected English native answer: Is that Tina?

- Predicted Persian native answer: (Aya shoma Tina hastid?) Are you Tina.?

\section{Situation 9: You want to introduce yourself on the phone.}

- You say:

- $\quad$ Expected English native answer: This is Tom.

- Predicted Persian native answer: (Man Ali hastam) I am Ali.

Situation 10: You want to say to your doctor that you have used your all your pills.

- You say:

- $\quad$ Expected English native answer: I took all my pills.

- Predicted Persian native answer: (Man hame ghorsamo khordam) I ate all my pills.

Situation 11: Your teacher wants you to name the rooms in your house.

- You say:

- Expected English native answer: Living room, bedroom, kitchen, bathroom, dining room.

- Predicted Persian native answer: Living room, bedroom, dining room, NOT kitchen \& bathroom.

Situation 12: You are a university student. Your professor said that you will have a test next week. You 
want to report this to your friend who was absent.

- You say: the teacher will an exam next week.

- Expected English native answer: give us

- Predicted Persian native answer: take

Situation 13: Your friend is in a hospital. You go there to see him. You see him lying on a bed. - You say:

- $\quad$ Expected English native answer: Oh, are you OK?

- $\quad$ Predicted Persian native answer: (Khoda bad nadeh) May God not bring you bad.

Situation 14: Your friend tells you that he has a terrible health problem therefore, you want to show that you are sympathetic about his problem.

- You say:

- $\quad$ Expected English native answer: I'm sorry to hear it; that's too bad.

- $\quad$ Predicted Persian native answer: (Moteassefam) I'm sorry.

Situation 15: Your friend tells you that his toothache is gone and you want to show that you are happy about it.

- You say:

- $\quad$ Expected English native answer: I'm glad to hear it.

- $\quad$ Predicted Persian native answer: (Veghean? Kheili khoshhal shodam/ khoda ro shokr) really? I got really happy/ thank God.

Situation 16: You are at one of your classmate's home whom you don't know very well. He asks, "would you like some tea?" and you want to say 'yes'.

- You say:

- Expected English native answer: Yes please!

- $\quad$ Predicted Persian native answer: (Mammnoon misham, age zahmati nist; toro khoda zahmat nakesh; razi be be zahmate shoma nistam) I'm grateful, if it is not hard.

Situation 17: Your brother tells you that he isn't going to the family reunion tonight. You want to ask him why he doesn't want to join you.

You say:

- $\quad$ Expected English native answer: Why not?

- $\quad$ Predicted Persian native answer: (Bara chi nemikhay biyay?) Why don't you want to come?

Situation 18: Your friend is explaining why he was absence for a class. You want to show that you understand the situation.

- You say: 
- $\quad$ Expected English native answer: I see.

- Predicted Persian native answer: (Ke intor) I understand / OK.

Situation 19: You invited one of your friends to dinner. Now you want to tell him or her to eat.

- You say:

- $\quad$ Expected English native answer: Help yourself (please).

- Predicted Persian native answer: (Befarmaeed, meil konid, lotfan ta'arof nakonid) Here you are, eat please. Please don't complement.

Situation 20: You and somebody else, whom you don't know, are standing at a door. You want to ask him or her to go first.

- You say:

- $\quad$ Expected English native answer: After you, please.

- Predicted Persian native answer: (Aval shoma befarmaeed) You first please.

\section{Rsasouli and Bagherzadeh, (2012).}

Note: This is not the students' copy. In this copy the Expected English native answer and the Predicted Persian native speaker answers were also included to show the differences in these situations in the two languages. 